\title{
Effects of Aspirin on Pregnancy Outcome and Serum Endothelin-1 and Thrombomodulin Levels in Pregnancy Patients with Chronic Hypertension
}

\author{
Yu Cai1 ${ }^{*}$, Jianjun Zhai', Bibo Feng1, Rui Chen², Xingyue Tian1 \\ ${ }^{1}$ Department of Gynecology and Obstetrics, Beijing Tongren Hospital Affiliated to Capital Medical University, Beijing, China \\ ${ }^{2}$ Department of Laboratory Medicine, Beijing Tongren Hospital Affiliated to Capital Medical University, Beijing, China \\ Email: *caiyu892002@sian.com
}

How to cite this paper: Cai, Y., Zhai, J.J., Feng, B.B., Chen, R. and Tian, X.Y. (2021) Effects of Aspirin on Pregnancy Outcome and Serum Endothelin-1 and Thrombomodulin Levels in Pregnancy Patients with Chronic Hypertension. Open Journal of Obstetrics and Gynecology, 11, 1073-1080. https://doi.org/10.4236/ojog.2021.118100

Received: August 5, 2021

Accepted: August 24, 2021

Published: August 27, 2021

Copyright $\odot 2021$ by author(s) and Scientific Research Publishing Inc. This work is licensed under the Creative Commons Attribution International License (CC BY 4.0).

http://creativecommons.org/licenses/by/4.0/

(c) (i) Open Access

\begin{abstract}
Objective: To investigate the effect of aspirin on pregnancy outcome and serum levels of endothelin-1 (ET-1) and thrombomodulin (TM) in pregnancy patients with chronic hypertension. Methods: Selected patients with chronic hypertension (mild to moderate) during pregnancy, who were enrolled and delivered in the Beijing Tongren Hospital Department of Obstetrics and Gynecology between January 1, 2019 and December 30, 2020. The patients were randomly divided into control group (60) and experimental group (60). The control group was treated with labetalol and the test group was treated with labetalol and aspirin. The therapeutic effect and pregnancy outcome of the two groups were compared. The serum levels of ET-1 and TM were measured before treatment and one week after treatment. Results: Systolic blood pressure (SBP) decreased significantly one week after treatment in the two groups $(\mathrm{P}<0.05)$. One week after treatment, the values of ET-1 and TM in the experimental group were significantly lower than those in the Control Group, the difference is statistically significant $(\mathrm{P}<0.05)$. The incidence of Preeclampsia, intrauterine growth retardation, oligohydramnios, placental abruption, Cesarean section and preterm birth in the experimental group was significantly lower than that in the control group. There was significant difference between the two groups, especially Preeclampsia and Intrauterine Growth Retardation $(\mathrm{P}<0.05)$. Conclusion: Besides routine treatment, aspirin can improve the outcome of pregnant women with chronic hypertension, which may be related to the regulation of ET-1 and TM by aspirin.
\end{abstract}

\section{Keywords}

Pregnancy with Chronic Hypertension, Aspirin, Maternal and Fetal 


\section{Introduction}

Chronic hypertension $(\mathrm{CH})$ is a high risk factor associated with hypertensive disorders of pregnancy (HPD). At present, there are more and more patients with chronic hypertension in pregnancy. The main complications are preeclampsia and placental abruption. How to reduce its complications and adverse outcomes is the focus of current obstetrics and gynecology research. Labetalol Hydrochloride is the most commonly used drug in the clinical treatment of HPD, but the single long-term use of a drug, sometimes the effect is not ideal; aspirin is the most commonly used drug in internal medicine, it has the functions of protecting vascular endothelium, inhibiting the production of vascular substances, inhibiting platelet aggregation and antithrombotic etc. [1]. Studies have shown that vascular endothelial damage is not only the pathological result of hypertension, but also the pathogenic factor of hypertension [2] [3]. Endothelin-1 (ET-1) is the most potent vasoactive substance, which can effectively regulate human Hemodynamics and blood pressure. Thrombomodulin (TM) is a marker of Endothelium injury and dysfunction [4] [5] [6]. The aim of this study was to investigate the effect of aspirin on pregnancy outcome and serum levels of endothelin-1 (ET-1) and thrombomodulin (TM) in pregnancy patients with chronic hypertension in order to provide reference for clinical treatment.

\section{Materials and Methods}

\subsection{Materials}

Collected data on 120 pregnant women with chronic hypertension who were filed at Beijing Tongren Hospital of Capital Medical University from January 1, 2019 to December 30, 2020. Patients with hypertension who were filed 12 weeks ago were divided into a control group and a test group according to whether they were willing to take aspirin enteric-coated tablets. There were 60 people in the control group, aged 20 to 39 years old, with an average age of $(29.86 \pm 3.74)$ years old, including 38 cases of moderate hypertension and 22 cases of mild hypertension. There were 60 people in the test group, aged from 21 to 38 years old, with an average age of $(30.15 \pm 4.06)$ years, including 37 cases of moderate hypertension and 23 cases of mild hypertension. There was no statistical difference between the two groups ( $P>0.05)$. Inclusion criteria: 1$)$ In line with the diagnosis history of hypertension, pregnant women with systolic blood pressure $\geq 140 \mathrm{~mm} \mathrm{Hg}$ and/or diastolic blood pressure $\geq 90 \mathrm{mmHg}$, but systolic blood pressure $<170$ and/or diastolic blood pressure $<110 \mathrm{mmhg}$; 2) No previous history of treatment; 3) Natural conception, first child, single pregnancy; 4) Patients who can follow up on time during pregnancy. Exclusion criteria: 1) Severe and chronic high in early pregnancy; 2) Twin pregnancy; 3) Miscarriage; 4) Com- 
bined medical diseases: heart, brain, liver and kidney disease, diabetes and severe anemia (aplastic anemia, thalassemia) etc.); 5) those with immune diseases; 6) those with mental illness; 7) Patients failing to follow up on time; 8) Change the treatment plan midway. This study has been approved by the Medical Ethics Committee of our hospital, and all research subjects have signed an informed consent form.

\subsection{Experimental Methods}

The Control Group was given routine treatment, labetalol hydrochloride tablets (made by Jiangsu desano Pharmaceutical Co., Ltd, batch number: Standard Chinese Medicine H32026120, specification: $100 \mathrm{mg} /$ tablet), taken orally after meals, 1 tablet/time, 2 times/day. The experimental group was treated with Aspirin enteric-coated tablets (Beijing Kangbide Pharmaceutical Co., Ltd., standard Chinese Medicine H11022430, specification: $0.25 \mathrm{~g} /$ tablet) and Aspirin $75 \mathrm{mg}$, QD. The fasting serum was taken one week after treatment. Pregnant women in the experimental group were normally given aspirin orally until 35 weeks, unless there was abnormal bleeding or temporary termination of pregnancy. Labetalol was given to both groups of patients until after delivery.

Observation Index: 1) Curative Effect: Contraction of two groups was recorded after 7 days of treatment. Systolic and diastolic blood pressure was measured at rest, and their mean values were taken 3 times. 2) adverse pregnancy outcomes: the adverse pregnancy outcomes in both groups were statistically analyzed, including complications of pre-eclampsia, intrauterine growth retardation, oligohydramnios, placental abruption, Cesarean section, preterm Labor, etc. 3) serum parameters: $4 \mathrm{Ml}$ of fasting venous blood was drawn before treatment and 7 days after treatment, and was centrifuged at 3200 RPM for $7 \mathrm{mi}-$ nutes, the levels of ET-1 and TM were detected by radioimmunoassay, and the operation was carried out strictly according to the instruction of the Kit, which was purchased from Shanghai Jingkang Biological Engineering Co, China. 4) adverse reactions: compare the incidence of heart palpitations, hypotension, chest tightness, edema and other adverse reactions between the two patients.

Statistical method: statistical data using SPSS 20.0, the counting data were tested by $x^{2}$ test or rank sum test, the normal distribution data were expressed by mean \pm standard deviation $(x \pm s)$, and t test was used for comparison among groups, $\mathrm{P}<0.05$, which had statistical significance.

\section{Result}

The effect of Aspirin on systolic blood pressure in pregnancy patients with chronic hypertension

There was no significant difference in systolic blood pressure between the two groups before Treatment $(\mathrm{P}>0.05)$, but the systolic blood pressure decreased significantly one week after Treatment $(\mathrm{P}<0.05)$, See Table 1 .

The effect of Aspirin on ET-1 and TM in pregnancy patients with chronic 


\section{hypertension}

There was no significant difference between the two groups before Treatment $(\mathrm{P}>0.05)$. One week after treatment, the values of ET- 1 and TM in the experimental group were significantly lower than those in the Control Group $(\mathrm{P}<$ 0.05), See Table 2. After treatment, the serum ET-1 and TM values in each group were significantly lower than those before treatment $(P<0.05)$, See Table 3.

\section{Comparison of adverse pregnancy outcomes between two groups}

The incidence of Preeclampsia, intrauterine growth retardation (IUGR), oligohydramnios, placental abruption, Cesarean section and preterm birth in the experimental group was significantly lower than that in the control group. In particular, the difference between the two groups of preeclampsia and intrauterine growth retardation was statistically significant $(\mathrm{P}<0.05)$, but the differences in the incidence of amniotic fluid, placental abruption, cesarean section, and preterm delivery were not statistically significant $(P>0.05)$. See Table 4 . Three patients in the control group and one patient in the test group were excluded from taking aspirin because of poor blood pressure control by oral labenol alone.

Table 1. Changes in systolic blood pressure at different time points in each group (mmHg).

\begin{tabular}{cccc}
\hline group & $\mathrm{N}$ & Before treatment & one week after treatment \\
\hline Control & 60 & $164.59 \pm 14.29$ & $130.63 \pm 12.54$ \\
Test & 60 & $165.83 \pm 13.72$ & $111.56+ \pm 11.71$ \\
$\mathrm{t}$ & & 0.485 & 8.609 \\
$\mathrm{P}$ & 0.613 & 0.000 \\
\hline
\end{tabular}

Table 2. Comparison of ET-1 and TM in serum between two groups.

\begin{tabular}{cccccc}
\hline \multirow{2}{*}{ group } & \multirow{2}{*}{$\mathrm{N}$} & \multicolumn{2}{c}{ Before treatment } & \multicolumn{2}{c}{ one week after treatment } \\
\cline { 3 - 6 } & & $\mathrm{ET}-1(\mathrm{ng} / \mathrm{l})$ & $\mathrm{TM}(\mathrm{ng} / \mathrm{ml})$ & $\mathrm{ET}-1(\mathrm{ng} / \mathrm{l})$ & $\mathrm{TM}(\mathrm{ng} / \mathrm{ml})$ \\
\hline Control & 60 & $89.82 \pm 8.71$ & $47.23 \pm 10.65$ & $67.79 \pm 8.54$ & $23.31 \pm 9.72$ \\
Test & 60 & $90.62 \pm 6.75$ & $46.67 \pm 11.48$ & $41.65 \pm 6.63$ & $12.35 \pm 8.62$ \\
$\mathrm{t}$ & & 0.670 & 0.223 & 18.476 & 6.535 \\
$\mathrm{P}$ & & 0.516 & 0.762 & 0.000 & 0.000 \\
\hline
\end{tabular}

Table 3. Comparison of ET-1 and TM in each group before and after treatment.

\begin{tabular}{|c|c|c|c|c|c|c|c|c|c|}
\hline \multirow[t]{2}{*}{ group } & \multirow[t]{2}{*}{$\mathrm{N}$} & \multicolumn{2}{|c|}{ ET-1 (ng/l) } & \multirow[t]{2}{*}{$\mathrm{t}$} & \multirow[t]{2}{*}{$\mathrm{P}$} & \multicolumn{2}{|c|}{$\mathrm{TM}(\mathrm{ng} / \mathrm{ml})$} & \multirow[t]{2}{*}{$\mathrm{t}$} & \multirow[t]{2}{*}{$\mathrm{P}$} \\
\hline & & Before treatment & $\begin{array}{c}\text { one week after } \\
\text { treatment }\end{array}$ & & & Before treatment & $\begin{array}{c}\text { one week after } \\
\text { treatment }\end{array}$ & & \\
\hline Control & 60 & $89.82 \pm 8.71$ & $67.79 \pm 8.54$ & 13.996 & 0.000 & $47.23 \pm 10.65$ & $23.31 \pm 9.72$ & 13.738 & 0.000 \\
\hline Test & 60 & $90.62 \pm 6.75$ & $41.65 \pm 6.63$ & 40.106 & 0000 & $46.67 \pm 11.48$ & $12.35 \pm 8.62$ & 34.215 & 0.000 \\
\hline
\end{tabular}


Table 4. Pregnancy outcome of pregnancy with chronic hypertension.

\begin{tabular}{|c|c|c|c|c|c|c|c|}
\hline group & $\mathrm{N}$ & pre-eclampsia & $\begin{array}{c}\text { intrauterine } \\
\text { growth retardation }\end{array}$ & oligohydramnios & $\begin{array}{l}\text { placental } \\
\text { abruption }\end{array}$ & $\begin{array}{l}\text { cesarean } \\
\text { section }\end{array}$ & $\begin{array}{c}\text { preterm } \\
\text { Labor }\end{array}$ \\
\hline Control & 57 & 18 & 14 & 12 & 3 & 11 & 15 \\
\hline Test & 59 & 5 & 5 & 7 & 0 & 5 & 8 \\
\hline $\mathrm{X}^{2}$ & & 9.431 & 5.478 & 1.787 & 3.188 & 2.8562 & 2.987 \\
\hline $\mathrm{P}$ & & 0.000 & 0.020 & 0.176 & 0.063 & 0.115 & 0.109 \\
\hline
\end{tabular}

\section{Discussion}

Hypertension is a common chronic disease in China, and it is also one of the most important risk factors of cardiovascular and cerebrovascular diseases [7]. However, chronic hypertension in pregnancy is one of the four common causes of maternal death in obstetrics and gynecology. If chronic hypertension in pregnancy is poorly controlled, it will be accompanied by preeclampsia and increase maternal and infant mortality. Studies have shown that hypertension is caused by vascular endothelial damage, and the physiological and pathological hypercoagulability of pregnancy can easily lead to intravascular thrombosis in the uterus and placenta. Insufficient placental perfusion leads to adverse pregnancy outcomes. Miscarriage can occur in the early stage, and the late stage is related to preeclampsia, fetal growth restriction, premature delivery, stillbirth, and placental abruption.

There was no significant difference in systolic blood pressure between the two groups before Treatment $(\mathrm{P}>0.05)$, but the systolic blood pressure decreased significantly one week after Treatment $(\mathrm{P}<0.05)$ [1] [8]. Rabenol combined with low-dose aspirin has a significant effect in lowering blood pressure without increasing the incidence of adverse reactions, and the effect is ideal. This may be the two drugs from the different mechanism of action, play a synergistic antihypertensive effect. Labetalol is a B adrenergic inhibitor, which is recognized as one of the safe and effective drugs for hypertensive disorder complicating pregnancy. Once in the body, it can lower blood pressure by dilating blood vessels and reducing peripheral resistance [1] [9]. Aspirin acts as an anticoagulant and improves local blood supply by inhibiting Cyclooxygenase, reducing arachidonic acid, and producing antiplatelet and antithrombotic effects, reduced the sensitivity of blood vessels to the active substances to a certain extent, resulting in vasodilation and hypotension [10] [11]. In pregnancy with chronic hypertension, labenol is the first choice to lower blood pressure, but with aspirin, the vasoconstrictor produced by blood vessel itself can be solved. In this way, the combination of the two not only has a synergistic effect on lowering blood pressure, but also avoids the risk of drug resistance of simply expanding blood vessels with labetalol.

Endothelial dysfunction increases systemic vascular resistance, leading to the development of hypertension [12] [13]. The results showed that there was no 
significant difference between the two groups in ET-1 and TM before treatment $(\mathrm{P}>0.05)$. One week after treatment, the values of ET-1 and TM in the experimental group were significantly lower than those in the Control Group $(\mathrm{P}<$ 0.05). After treatment, the serum ET-1 and TM values in each group were significantly lower than those before treatment $(\mathrm{P}<0.05)$, which may be related to the improvement of Vascular endothelial function and the reduction of vasoconstrictor production by aspirin [14]. ET-1 is the most potent endogenous vasoactive peptide, which can promote vasoconstriction and vascular smooth muscle proliferation [6] [15] [16]. Studies have shown [17] [18] [19] that there are certain differences in ET-1 levels in patients with different types of hypertensive disorders in pregnancy, and it is closely related to the left ventricular function parameters and renal hemodynamic indicators, which can be used to judge the condition of patients with hypertensive disorder complicating pregnancy. TM is a thrombin receptor synthesized by vascular endothelial cells and located on the cell surface. In diseases accompanied by vascular endothelial damage, TM falls off in the blood and can cause an increase in plasma TM concentration. It is often considered to reflect microvascular endothelial cell damage and signs of dysfunction. In this study, aspirin can effectively reduce serum ET-1 and TM levels, suggesting that this treatment plan can effectively improve human microcirculation. According to the principle of action, aspirin can reduce the generation of oxygen free radicals, and resist peroxide damage, and effectively maintain the integrity of endothelial cells [20], and then reduce the level of ET-1 and TM effectively.

The incidence of preeclampsia, Intrauterine Growth Retardation, oligohydramnios, placental abruption, Cesarean section and preterm birth in the experimental group was significantly lower than that in the control group. In particular, the difference between the two groups of preeclampsia and intrauterine growth retardation was statistically significant $(\mathrm{P}<0.05)$, but the differences in the incidence of amniotic fluid, placental abruption, cesarean section, and preterm delivery were not statistically significant $(P>0.05)$. However, the incidence of adverse pregnancy outcomes was significantly lower in women who were treated with aspirin. This is consistent with studies [1] [21] [22] [23] that may be due to the anticoagulant effect of Aspirin and its role in improving local blood supply, protecting the endothelium of blood vessels and avoiding the production of vasoconstrictors, it can effectively control the blood pressure of the human body and restore the normal blood supply of the placenta and reduce the occurrence of preeclampsia and intrauterine growth retardation of the fetus, so that the fetus can gradually normal development, and obtain a good maternal and infant pregnancy outcome. Data on Chinese population has been relatively few.

\section{Summary}

In summary, the addition of aspirin in pregnancy with chronic hypertension can effectively control blood pressure, and improve pregnancy outcome to a certain 
extent, and it is safe and effective. Its mechanism of action may be related to the regulation of serum ET-1 and TM levels.

\section{Acknowledgements}

Rui Chen, teacher in the department of laboratory medicine, Beijing Tongren Hospital affiliated to Capital Medical University, provided technical support. I would like to extend my heartfelt thanks to all of my colleagues who have worked hard on this subject.

\section{Fund of the Project}

Wu Jieping Medical Foundation Clinical Research Special Fund: 320.6750.1250.

\section{Conflicts of Interest}

The authors have declared that no competing interests exist.

\section{References}

[1] Guo, L.M., Liu, Y.X. and Liu, X.L. (2021) Effect of Aspirin Combined with Labetalol on Pregnancy Outcome and Serum Levels of ET-1 and TSP-1 in Patients with Gestational Hypertension. Journal of Jinzhou Medical University, 42, 54-57.

[2] Sitohy, B., Chang, S., Sciuto, T.E., et al. (2017) Early Actions of Antivascular Endothelial Growth Factor/Vascular Endothelial Growth Factor Receptor Drugs on Angiogenic Blood Vessels. The American Journal of Pathology, 187, 2337-2347. https://doi.org/10.1016/j.ajpath.2017.06.010

[3] Goto, K., Ohtsubo, T. and Kitazono, T. (2018) Endothelium-Dependent Hyperpolarization (EDH) in Hypertension: The Role of Endothelial Ion Channels. International Journal of Molecular Sciences, 19, E315. https://doi.org/10.3390/ijms19010315

[4] Dhaun, N. and Webb, D.J. (2019) Endothelins in Cardiovascular Biology and Therapeutics. Nature Reviews Cardiology, 16, 491-502. https://doi.org/10.1038/s41569-019-0176-3

[5] Levin, E.R. (1996) Endothelins as Cardiovascular Peptides. American Journal of Nephrology, 16, 246-251. https://doi.org/10.1159/000169004

[6] Li, C.B., Xu, L.N., Bu, X.X., et al. (2021) The Value of Soluble Thrombomodulin in Evaluating Endothelial Injury in Patients with Kidney Disease. National Medical Journal of China, 101, 1812-1815.

[7] Zhang, Y.Q. (2019) The Value of Microalbuminuria in Cardiovascular Risk Assessment in Patients with Hypertension. Chinese Journal of Hypertension, 27, 585-590.

[8] Costa, A.C., Reina-Couto, M., Albino-Teixeira, A., et al. (2017) Aspirin and Blood Pressure: Effects When Used Alone or in Combination with Antihypertensive Drugs. Revista Portuguesa de Cardiologia, 36, 551-567. https://doi.org/10.1016/j.repce.2017.05.008

[9] Sridharan, K. and Sequeira, R.P. (2018) Drugs for Treating Severe Hypertension in Pregnancy: A Network Meta-Analysis and Trial Sequential Analysis of Randomized Clinical Trials. British Journal of Clinical Pharmacology, 84, 1906-1916. https://doi.org/10.1111/bcp.13649 
[10] Liu, F.-M., Zhao, M., Wang, M., Yang, H.-L., et al. (2016) Effect of Regular Oral Intake of Aspirin during Pregnancy on Pregnancy Outcome of High-Risk Pregnancy-Induced Hypertension Syndrome Patients. European Review for Medical and Pharmacological Sciences, 20, 5013-5016.

[11] Ortiz, C., Rondeau, N.U., Moore, L.E., et al. (2018) Parental Age and the Risk of Gestational Hypertension and Preeclampsia. Southern Medical Journal, 111, 544-548. https://doi.org/10.14423/SMJ.0000000000000854

[12] Konukoglu, D. and Uzun, H. (2017) Endothelial Dysfunction and Hypertension. Advances in Experimental Medicine and Biology, 956, 511-540. https://doi.org/10.1007/5584_2016 90

[13] Mordi, I., Mordi, N., Delles, C., et al. (2016) Endothelial Dysfunction in Human Essential Hypertension. Journal of Hypertension, 34, 1464-1472.

https://doi.org/10.1097/HJH.0000000000000965

[14] Dzeshka, M.S., Shantsila, A. and Lip, G.Y. (2016) Effects of Aspirin on Endothelial Function and Hypertension. Current Hypertension Reports, 18, 83. https://doi.org/10.1007/s11906-016-0688-8

[15] Palacios-Ramírez, R., Hernanz, R., Martín, A., et al. (2019) Pioglitazone Modulates the Vascular Contractility in Hypertension by Interference with ET-1 Pathway. Scientific Reports, 9, Article No. 16461. https://doi.org/10.1038/s41598-019-52839-6

[16] Ou, M., Zhao, H., Ji, G., et al. (2020) Long Noncoding RNA MALAT1 Contributes to Pregnancy-Induced Hypertension Development by Enhancing Oxidative Stress and Inflammation through the Regulation of the miR-150-5p/ET-1 Axis. The FASEB Journal, 34, 6070-6085. https://doi.org/10.1096/fj.201902280R

[17] Budzyń, M., Gryszczyńska, B., Boruczkowski, M., et al. (2019) The Endothelial Status Reflected by Circulating Endothelial Cells, Circulating Endothelial Progenitor Cells and Soluble Thrombomodulin in Patients with Mild and Resistant Hypertension. Vascular Pharmacology, 113, 77-85. https://doi.org/10.1016/j.vph.2018.12.005

[18] Turner, R.J., Bloemenkamp, K.W., Bruijn, J.A., et al. (2016) Loss of Thrombomodulin in Placental Dysfunction in Preeclampsia. Arteriosclerosis, Thrombosis, and Vascular Biology, 36, 728-735. https://doi.org/10.1161/ATVBAHA.115.306780

[19] Stratton, R.J., Pompon, L., Coghlan, J.G., et al. (2000) Soluble Thrombomodulin Concentration Is Raised in Scleroderma Associated Pulmonary Hypertension. Annals of the Rheumatic Diseases, 59, 132-134. https://doi.org/10.1136/ard.59.2.132

[20] Gu, W., Lin, J., Hou, Y.Y., Lin, N., et al. (2020) Effects of Low-Dose Aspirin on the Prevention of Preeclampsia and Pregnancy Outcomes: A Randomized Controlled Trial from Shanghai, China. European Journal of Obstetrics \& Gynecology and Reproductive Biology, 248, 156-163. https://doi.org/10.1016/j.ejogrb.2020.03.038

[21] Roberge, S., Bujold, E. and Nicolaides, K.H. (2018) Aspirin for the Prevention of Preterm and Term Preeclampsia: Systematic Review and Metaanalysis. American Journal of Obstetrics \& Gynecology, 218, 287-293. https://doi.org/10.1016/j.ajog.2017.11.561

[22] Lecarpentier, E. and Haddad, B. (2020) Aspirin for the Prevention of Placenta-Mediated Complications in Pregnant Women with Chronic Hypertension. Journal of Gynecology Obstetrics and Human Reproduction, 49, Article ID: 101845. https://doi.org/10.1016/j.jogoh.2020.101845

[23] Xiang, X., Wang, F., Zhao, N., et al. (2020) Treatment of Pregnancy-Induced Hypertension Compared with Labetalol, Low Dose Aspirin and Placebo. Cellular and Molecular Biology (Noisy-le-grand), 66, 9-13. 